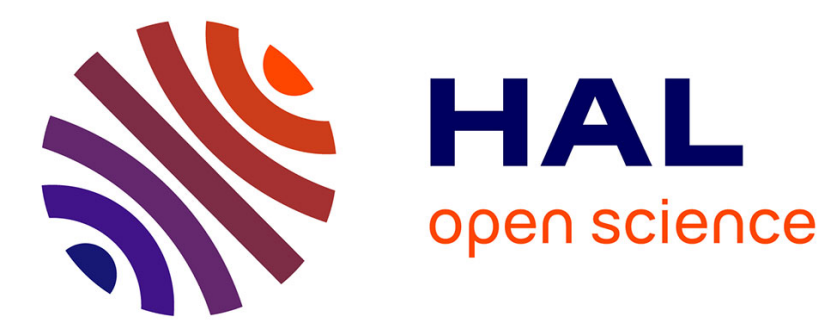

\title{
Internal decision-making rules and collusion
}

\author{
Alexander Rasch, Achim Wambach
}

\section{To cite this version:}

Alexander Rasch, Achim Wambach. Internal decision-making rules and collusion. Journal of Economic Behavior and Organization, 2009, 72 (2), pp.703. 10.1016/j.jebo.2009.07.008 . hal-00722791

\section{HAL Id: hal-00722791 \\ https://hal.science/hal-00722791}

Submitted on 4 Aug 2012

HAL is a multi-disciplinary open access archive for the deposit and dissemination of scientific research documents, whether they are published or not. The documents may come from teaching and research institutions in France or abroad, or from public or private research centers.
L'archive ouverte pluridisciplinaire HAL, est destinée au dépôt et à la diffusion de documents scientifiques de niveau recherche, publiés ou non, émanant des établissements d'enseignement et de recherche français ou étrangers, des laboratoires publics ou privés. 


\section{Accepted Manuscript}

Title: Internal decision-making rules and collusion

Authors: Alexander Rasch, Achim Wambach

PII:

DOI:

S0167-2681(09)00188-7

Reference: doi:10.1016/j.jebo.2009.07.008

JEBO 2425

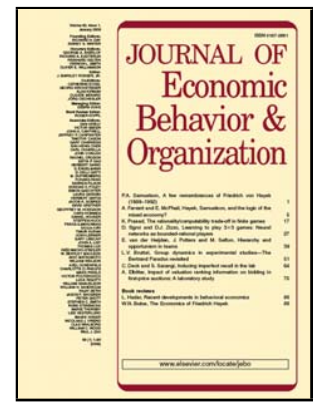

To appear in: Journal of Economic Behavior \& Organization

Received date: $\quad 13-2-2008$

Revised date: 24-7-2009

Accepted date: $\quad$ 24-7-2009

Please cite this article as: Rasch, A., Internal decision-making rules and collusion, Journal of Economic Behavior and Organization (2008), doi:10.1016/j.jebo.2009.07.008

This is a PDF file of an unedited manuscript that has been accepted for publication. As a service to our customers we are providing this early version of the manuscript. The manuscript will undergo copyediting, typesetting, and review of the resulting proof before it is published in its final form. Please note that during the production process errors may be discovered which could affect the content, and all legal disclaimers that apply to the journal pertain. 


\title{
Internal decision-making rules and collusion*
}

\author{
Alexander Rasch ${ }^{\dagger} \quad$ Achim Wambach ${ }^{\ddagger}$
}

July 2009

We study the impact of internal decision-making structures on the stability of collusive agreements. To this end, we use a three-firm spatial competition model where two firms belong to the same holding company. The holding company can decide to set prices itself or to delegate this decision to its local units. It is shown that when transportation costs are high, collusion is more stable under delegation. Furthermore, collusion with maximum prices is more profitable if price setting is delegated to the local units. Profitability is reversed for low discount factors.

JEL classification: D43, L13, L41.

Keywords: collusion, delegation, holding company, merger, Nash bargaining solution.

${ }^{*}$ We would like to thank Johannes Binswanger, Oliver Gürtler, Joseph E. Harrington Jr., Jesko Herre, Wanda Mimra, Patrick Rey, Vanessa von Schlippenbach, and Gregor Zöttl for very helpful comments and discussions. We also wish to thank two anonymous referees for their very useful suggestions. Part of this work was done while Alexander Rasch was visiting the Midi-Pyrénées School of Economics (MPSE) of the University of Toulouse 1. He would like to express his sincere thanks for the hospitality he experienced throughout his stay.

$\dagger$ Address: University of Cologne, Department of Economics, Albertus-Magnus-Platz, 50923 Cologne, Germany. Email: rasch@wiso.uni-koeln.de

${ }^{\ddagger}$ Corresponding author. Address: University of Cologne, Department of Economics, AlbertusMagnus-Platz, 50923 Cologne, Germany. Email: wambach@wiso.uni-koeln.de. 


\section{Introduction}

Antitrust and competition authorities have to evaluate the implications of a merger for post-merger competition. To prevent coordinated effects in an industry, authorities have two types of remedies at their disposal: structural and non-structural (behavioral) remedies. The former are often associated with (partial) divestiture of assets owned by the acquiring firm. However, they may also involve a so-called spin-off, where the shares of an acquired company are transferred to the stockholders of the acquiring firm and where the acquired firm is maintained as a separate entity. ${ }^{1}$ Non-structural remedies may involve the delegation of decision-making powers. For instance, as Campbell and Halladay (2002, p. 10) report, the Commissioner of Competition, who is the head of the Competition Bureau in Canada, accepted the "maintenance of the acquired firm as a separate and distinct corporate entity with a separate board of directors" in some decisions ${ }^{2}$ as a remedy to prevent anti-competitive behavior. In this article, we are interested in the implications for collusion when the (acquired) firms are kept as separate entities with certain decision-making powers.

At first sight, the above logic behind such remedies seems compelling. Giving decision-making powers away tends to have a similar effect as an increase in the number of firms in the market which makes it harder to sustain collusive behavior. However, this standard reasoning ignores how the centralization of decision powers affects the other firms' incentives to collude. We show that while it turns out to be true that from the point of view of the holding company, its incentive to deviate from a collusive agreement is increased if it delegates decision powers to local units, the other firms in the market may be less likely to deviate if decisions are made locally.

We use a three-firm spatial model à la Salop (1979). In order to account for different decision-making structures, there is a holding company which owns two of the firms. The holding company decides whether to delegate the price setting to its local units or not. As shown in various contributions in the literature on mergers, the holding company indeed prefers to keep the pricing decision by itself in the competitive case. This is easily understood by noting that when delegating the price setting to the local units, there are three firms competing in the market instead of two (which is the case when the holding company keeps authority). This implies stronger competition, and thus lower prices and lower profits. So if discount factors are low and collusion with maximum prices is not possible (although a weaker form of collusion is still possible, see the third section), the holding company will set prices itself. If, however, the discount factor is sufficiently high and collusion at maximum prices is possible, the picture changes. We assume that the colluding parties bargain over the collusive prices as in Harrington (1991) and Harrington et al. (2005). Then, although the disagreement payoff (which is the competitive outcome) is better for the holding company if it keeps decision powers, the overall outcome is better for

\footnotetext{
${ }^{1}$ This was the case in In re Procter 83 Gamble Co (see Shelanski and Sidak, 2001). As Timmins (1986) points out, a spin-off may be required if there is no viable purchaser in the market in the wake of a divestiture order by the court.

${ }^{2}$ This was the case in Canada Post/Purolator and Avis/Budget.
} 
the holding company if the local units negotiate (Proposition 1). Intuitively, this can be understood by noting that in the latter case, the 'collusive cake' has to be shared by three players, two of which belong to the holding company. In the former case, there are two players trying to get their share of the cake. ${ }^{3}$

These results have consequences for the stability of collusion at maximum prices. It is well known from the literature that collusion becomes less stable if there are more parties to it. So one would expect that here also collusion will break down more easily if the pricing is delegated to the local units as then three parties are involved in the collusion. In line with intuition, Lemma 2 shows that the critical discount factor, i.e. the discount factor where a party is just indifferent between colluding and deviating, is smaller for the holding company for the case where it keeps decision powers compared to the case where it delegates the pricing decision. However, in order to determine whether collusion is sustainable in the market as a whole, the outside firm's incentive to deviate from collusion becomes relevant. Indeed, as Lemma 3 shows, the critical discount factor of the outside firm is greater than the one for the holding company. Proposition 2 shows that maximum prices in the market are more likely to be sustained if the holding company delegates decision-making powers and if transportation costs are high. For low transportation costs, the result is reversed. Finally, Proposition 3 summarizes the results and discusses the case for intermediate and/or low discount factors where, as shown by Chang (1991), collusion does not break down completely but is still possible at lower collusive prices.

There has been a growing interest in understanding how different internal firm structures affect market outcomes. However, the literature focuses mainly on strategic implications of divisionalization for competition and the resulting profits, as well as on relative profits of insiders and outsiders in the context of mergers. What has been neglected in the contributions so far is an analysis of the implications of different decision-making regimes on the profitability and stability of collusive agreements. Baye et al. (1996) assume divisionalization by one firm, which increases the number of quantity-setting firms producing the same output in the industry. This drives down industry profit but the multidivisional firm enjoys a greater share of these profits. The authors show that the second effect is stronger which means that divisionalization is profitable. Huck et al. (2004) develop a model where a joint headquarter lets two divisions decide on output quantities. Additionally, it sets up an internal sequential game in which the divisions compete against one another and where there are internal information flows due to the sequential nature of the game. ${ }^{4}$ This implies that the market resembles a Stackelberg, rather than a Cournot, market. As a result, mergers may be profitable and welfare-improving even if the linear cost function is the same for all firms. At the same time, competitors are worse off

\footnotetext{
${ }^{3}$ This result resembles the classical case of quantity competition with three firms where the two merging firms usually lose out as they have the highest incentive to reduce quantity after the merger (so-called merger paradox). So a holding company prefers to merge but would rather leave decision powers with the local units. In our case, the holding company is weaker with respect to negotiating good conditions for itself as its marginal profits count less compared to a situation where the two local units bargain instead.

${ }^{4}$ The authors show that this sequential structure also arises endogenously when the divisions may make their own timing decisions.
} 
as their profits decrease. In a similar setup, Creane and Davidson (2004) come to the same conclusion.

The article by Levy and Reitzes (1992) is related to the present one in that it analyzes the implications of mergers for the stability of collusion. Unlike the present article, they look at the conditions under which firms actually find it profitable to merge. Contrary to the analysis in this article, firms are assumed to maximize industry profits in a collusive phase which means that firms' asymmetry is not accounted for. As a consequence, the profitability of a merger, once collusion can be achieved, is not an issue. In addition, a comparison between the deviating incentives of the merged firm and of the other firms in the market is not made.

The articles by Lambertini and Trombetta (2002) and Spagnolo (2005) are related to the present one with respect to the delegation of decision powers and its implications for collusion. Contrary to these contributions, we do not compare the effects of different (publicly observable) contract schemes for the stability of collusion, but consider different decision-making scenarios. ${ }^{5}$ When it comes to the internal decision-making structure actually preferred by the merging firms, Prechel et al. (1999) show in an empirical study that these firms tend to opt for decentralized decision making.

The article proceeds as follows. In the following section, we set up the model and look at the competitive case before we analyze collusion and the incentives to deviate. In the third section, we derive the critical discount factors and compare the outcomes as well as the profitability for the two decision-making regimes. The last section concludes.

\section{The model}

We want to capture the trade-off a holding company faces when having to decide about delegating decision-making powers under market collusion. To this end, we follow the well known Salop (1979) setup for a market of spatial competition with horizontal product differentiation. There are three firms with two firms (firms 2 and 3) being governed by a holding company. All three firms are located equidistantly from each other along a circular city with a circumference of 1 . In order to capture different internal decision-making structures, the holding company may either keep the pricing decision or give it away to both of its local units. ${ }^{6}$

We model collusive behavior following Friedman (1971) (so-called grim-trigger strategies): Firms tacitly agree to collude. So in every period the holding company and the third firm set collusive prices whenever no one deviated from the agreement in the previous period. If there is deviation, this triggers a price war and there is competition forever. A problem with the modeling by Friedman (1971) and with most models on collusive outcomes is that there are many prices which can be sustained in equilibrium. Usually the literature concentrates on those prices which

${ }^{5}$ Relatedly, Olaizola (2007) studies the effects of delegation on endogenous cartel formation among symmetric firms.

${ }^{6}$ Note that one may also think of a situation where the pricing decision is partially delegated only. This could be done by having local units take into account the other unit's (weighted) profits as well. 
maximize the overall collusive profit. This procedure might be considered reasonable as long as firms are symmetric. Here, however, the outside firm and the holding company differ. Therefore, we follow Harrington (1991) and Harrington et al. (2005) and assume that at an initial stage, the price-setting parties (implicitly) bargain over the collusive prices.

As is common for the analysis of collusion, we will later make use of the so-called critical discount factor in order to define the range of discount factors for which maximum collusive prices are sustainable. The critical discount factor according to Friedman (1971) is characterized as follows: ${ }^{7}$

$$
\delta \geq \bar{\delta}:=\frac{\pi^{D}-\pi^{C}}{\pi^{D}-\pi^{N}}
$$

where superscripts $C, D$, and $N$ denote profits in the collusive, the deviating, and the punishment (competitive Nash price equilibrium) cases, respectively. ${ }^{8}$

In what follows, we will derive the profits for all three situations. We start with the punishment case as the profits under price competition will be needed to derive the optimal collusive prices. $^{9}$

\subsection{Punishment through competition}

Customers of mass 1 are uniformly distributed along the unit circle and are interested in buying one product or none. They are assumed to derive a basic utility of 1 from purchasing the product offered by firm $i(i \in\{1,2,3\})$. Furthermore, a customer located at some distance $\Delta_{i}$ from firm $i$ has to incur (quadratic) transportation costs of $\tau \Delta_{i}^{2}$ when traveling to this firm. $p_{i}$ denotes the price charged by firm $i$. Hence, a customer derives the following net utility $u_{i}$ when buying from this firm:

$$
u_{i}=1-p_{i}-\tau \Delta_{i}^{2}
$$

We make the following assumption with respect to the transportation costs:

Assumption $10<\tau \leq 7 / 2=: \bar{\tau}$.

This assumption ensures that it is optimal for the market to be covered. ${ }^{10}$

\footnotetext{
${ }^{7}$ The critical discount factor can be derived from the requirement that profits from the collusive agreement must be higher than those from deviation and the ensuing punishment phase, i.e. $\pi^{C} /(1-\delta) \geq \pi^{D}+\delta \pi^{N} /(1-\delta)$.

${ }^{8}$ An alternative option would be the use of optimal punishments due to Abreu (1986, 1988) and Abreu et al. (1986) (so-called stick-and-carrot strategies). As Häckner (1996) shows, applying optimal punishments in the context of a setup à la Hotelling (1929) with quadratic transportation costs and symmetric firms gives qualitatively the same results with respect to the impact of product differentiation on the collusive price as in Chang (1991) who uses grim-trigger strategies. Therefore, we conjecture that our results would hold qualitatively for optimal punishments. In the present context with asymmetric firms, the derivation of such optimal punishments becomes non-tractable.

${ }^{9}$ The following section is a special case of the analysis in Posada and Straume (2004) who analyze firms' incentives to merge under partial merger and relocation.

${ }^{10}$ This result is derived in the appendix as part of the derivation of the collusive prices.
} 


\section{Centralized decision making}

We start by considering the case where the holding company makes the pricing decision. Denote by $x_{i}$ the position of the marginal customer located in between firm $i$ and the next firm in the clockwise direction (where subscript $c$ stands for centralization). Then, the indifferent customer between firms 1 (price $p_{1, c}^{N}$ ) and 2 (price $p_{h, c}^{N}$ where subscript $h$ stands for the holding company) can be obtained by solving

$$
p_{1, c}^{N}+\tau x_{1}^{2}=p_{h, c}^{N}+\tau\left(\frac{1}{3}-x_{1}\right)^{2}
$$

for $x_{1, c}^{N}$ which gives

$$
x_{1, c}^{N}=\frac{1}{6}-\frac{3\left(p_{1, c}^{N}-p_{h, c}^{N}\right)}{2 \tau} .
$$

Hence, from the profits for firm 1 and the holding company, i.e.

$$
\pi_{1, c}^{N}=2 p_{1, c}^{N}\left(\frac{1}{6}-\frac{3\left(p_{1, c}^{N}-p_{h, c}^{N}\right)}{2 \tau}\right)
$$

and

$$
\pi_{h, c}^{N}=2 p_{h, c}^{N}\left(\frac{1}{3}+\frac{3\left(p_{1, c}^{N}-p_{h, c}^{N}\right)}{2 \tau}\right),
$$

we can derive the optimal prices in the usual way. We then find the following equilibrium prices and profits:

$$
\begin{gathered}
p_{1, c}^{N}=\frac{4 \tau}{27}, \\
p_{h, c}^{N}=\frac{5 \tau}{27}, \\
\pi_{1, c}^{N}=\frac{16 \tau}{243},
\end{gathered}
$$

and

$$
\pi_{h, c}^{N}=\frac{25 \tau}{243}
$$

Note that given these prices, the basic utility is large enough so that every customer between two firms has indeed an incentive to join one of these firms, i.e. the market is covered.

We now turn to the case where the holding company gives away the pricing decision.

\section{Decentralized decision making}

Decentralized decision making is characterized by a situation where the two local units are in charge of price setting (subscript $d$ ). As a result, the punishment involves price competition between all three firms. We assume that the managers of the local units maximize the profits of their individual unit. 
Proceeding in the same way as before gives

$$
\begin{gathered}
p_{i, d}^{N}=\frac{\tau}{9}, \\
\pi_{i, d}^{N}=\frac{\tau}{27},
\end{gathered}
$$

and

$$
\pi_{h, d}^{N}=2 \pi_{i, d}^{N}=\frac{2 \tau}{27} .
$$

Note that the market is covered here as well.

To summarize we restate a familiar result that under competition the holding company will set higher prices. By setting prices itself, the holding company can avoid competing with itself for the customers located in between its two local units. As prices are strategic complements it follows immediately that firm 1 will charge a higher price if the holding company sets the prices for its units. These higher prices then translate into higher profits for the holding company as well as for firm 1.

We now proceed with analyzing the different scenarios under collusion.

\subsection{Collusive outcome}

In this section it is assumed that collusion is feasible. The incentives to defect from collusion are analyzed in the next subsection. Again, we have to distinguish between the two cases of internal decision making.

\section{Centralized decision making}

We start with the situation where all decisions are made by the holding company. Like Harrington (1991) and Harrington et al. (2005), we assume that under collusion prices will be set according to the Nash bargaining solution ${ }^{11}$, i.e. the maximization problem can be written as follows:

$$
\max _{p_{1, c}^{C}, p_{h, c}^{C}} \Pi_{c}^{C}:=\left(\pi_{1, c}^{C}-\pi_{1, c}^{N}\right)\left(\pi_{h, c}^{C}-\pi_{h, c}^{N}\right)
$$

where $\pi_{1, c}^{C}$ and $\pi_{h, c}^{C}$ are calculated by replacing $p_{1, c}^{N}$ and $p_{h, c}^{N}$ in equations (4) and (5) by $p_{1, c}^{C}$ and $p_{h, c}^{C}$, respectively. In the appendix, we provide a formal proof for the derivation of the optimal collusive prices. It is shown that the holding company will set its collusive price at the highest possible level such that the market is still covered. This means that the customer halfway between the holding company's local units will be left with zero utility, i.e. $p_{h, c}^{C}=1-\tau / 36$. At the same time, the outside firm charges a lower collusive price. This is due to the fact that starting from $p_{1, c}^{C}=p_{h, c}^{C}, \pi_{1, c}^{C}-\pi_{1, c}^{N}$ is lower than $\pi_{h, c}^{C}-\pi_{h, c}^{N}$. Thus, a small increase in $\pi_{1, c}^{C}$ (through a decrease of $p_{1, c}^{C}$ ) with a corresponding small reduction in $\pi_{h, c}^{C}$ increases the product.

\footnotetext{
${ }^{11}$ This solution was proposed by Nash (1950) (see also Osborne and Rubinstein, 1990, chapter 2).
} 


\section{Decentralized decision making}

Next, we are interested in the collusive prices if the holding company does not set the prices for its two local units. We assume that collusion is only feasible if all three firms participate, i.e. there is a grand coalition. The optimal outcome is therefore the solution to the following maximization problem:

$$
\max _{p_{i, d}^{C}} \Pi_{d}^{C}:=\left(\pi_{1, d}^{C}-\pi_{1, d}^{N}\right)\left(\pi_{2, d}^{C}-\pi_{2, d}^{N}\right)\left(\pi_{3, d}^{C}-\pi_{3, d}^{N}\right)=\left(\pi_{i, d}^{C}-\pi_{i, d}^{N}\right)^{3} .
$$

Due to the symmetric structure, the optimal collusive price is the same for all firms and is such that the indifferent customer in between any two firms is left with a utility of zero:

$$
p_{i, d}^{C}=1-\frac{\tau}{36} .
$$

Profits thus amount to

$$
\pi_{i, d}^{C}=\frac{1}{3}-\frac{\tau}{108}
$$

and

$$
\pi_{h, d}^{C}=2 \pi_{i, d}^{C}=\frac{2}{3}-\frac{\tau}{54} .
$$

We summarize our findings from this subsection in the following proposition:

Proposition 1 Comparing both decision-making regimes under collusion yields:

(a) $p_{1, c}^{C}<p_{h, c}^{C}$,

(b) $p_{h, c}^{C}=p_{i, d}^{C}$,

(c) $\pi_{1, c}^{C}>\pi_{1, d}^{C}$, and

(d) $\pi_{h, c}^{C}<\pi_{h, d}^{C}$.

Proof Ad (a) and (b): Follow from the derivation of the maximum collusive prices which is relegated to the appendix. Ad (c) and (d): Follow from (a) and (b).

If pricing decisions are delegated to the local units, all three firms charge the monopoly price of $1-\tau / 36$ and share the market equally (result (b)). If, however, the holding company keeps authority over prices, then it will be worse off. While its units still charge $1-\tau / 36$ (result (b)), firm 1 charges a lower price (result (a)), leaving less profit to the holding company. This result is not straightforward from the point of view of the holding company: The analysis of the competitive case showed that in the case of breakdown of collusion, a holding company fares better by keeping decision powers. This effect of a more favorable disagreement payoff leads to an increase in bargaining power which tends to lead to a higher collusive profit. On the other hand, as the parties bargain over the collusive prices, the holding company fares worse in bilateral negotiations. This is intuitively clear as by direct negotiations, the 'collusive cake', i.e. the profits generated by collusion, has to be divided among two players. If, however, the two local units negotiate for themselves, this 
cake is divided among three firms two of which are owned by the holding company. ${ }^{12}$ More formally, in equilibrium the profits of the holding company's local units enter the maximization problem additively in the former case (see equation (13)) while in the latter case, they enter quadratically (see equation (14)). A marginal increase in profits increases this expression more if profits enter quadratically.

The following observation will be relevant below: $\partial\left(\pi_{1, c}^{C}-\pi_{1, d}^{C}\right) / \partial \tau<0$, i.e. an increase in the transportation costs reduces the difference in the outside firm's collusive profits under both regimes. This can be explained by pointing out that the outside firm captures a market share of more than $1 / 3$ by charging a lower price than the holding company. However, as transportation costs increase, customers incur a higher disutility which means that this price would have to be lowered to a (much) larger extent - compared to the actual price - in order to reach the same market share. As a consequence, the outside firm's market share is reduced which leads to (relatively) lower profits since in the case of decentralization, there is only a price-reducing effect whenever transportation costs are increased.

Having determined the collusive prices, we next turn to the deviation incentives firms have.

\subsection{One-period deviation incentives}

We start with the simpler case where firm $i$ faces two rivals which charge a collusive price of $1-\tau / 36$. Then, a deviating firm may either seize only a share of the market by setting a moderate deviation price or it may cover the whole market through a very low price. Now consider the first situation: Determining firm $i$ 's deviation profit in the usual way, differentiating with respect to the deviation price, and solving for the optimal price for firm $i$ gives

$$
p_{1, c}^{D}=p_{i, d}^{D}=\frac{1}{2}+\frac{\tau}{24}
$$

In this case, the deviating firm's market share amounts to

$$
x_{1, c}^{D}=x_{i, d}^{D}=\frac{12+\tau}{16 \tau} .
$$

Hence, the deviating firm covers the whole market whenever $x_{1, c}^{D}=x_{i, d}^{D} \geq 1 / 2 \Leftrightarrow$ $\tau \leq 12 / 7=: \hat{\tau}$, i.e. when transportation costs are low. As the deviating firm cannot extend its market share further than that, it will charge a deviation price of

$$
\frac{1}{6}-\frac{3 p_{1, c}^{D}-3\left(1-\frac{\tau}{36}\right)}{2 \tau}=\frac{1}{2} \Leftrightarrow p_{1, c}^{D}=p_{i, d}^{D}=1-\frac{\tau}{4} .
$$

\footnotetext{
${ }^{12}$ One may argue that such a distribution of profits in the present scenario is due to the fact that all parties have the same bargaining power. Indeed, giving the holding company (sufficiently) more bargaining power when 'negotiating' with the outside firm would result in equal profits for all three (local) firms. However, we think that our specification is suitable insofar as factors that usually lead to different degrees of bargaining power like impatience, risk of breakdown, (legally binding) commitment tactics, etc. (see Muthoo, 1999) are not relevant here.
} 
We thus have the following outcome:

$$
p_{1, c}^{D}=p_{i, d}^{D}= \begin{cases}1-\frac{\tau}{4} & \text { if } \tau \leq \hat{\tau} \\ \frac{1}{2}+\frac{\tau}{24} & \text { else }\end{cases}
$$

and

$$
\pi_{1, c}^{D}=\pi_{i, d}^{D}= \begin{cases}1-\frac{\tau}{4} & \text { if } \tau \leq \hat{\tau} \\ \frac{(12+\tau)^{2}}{192 \tau} & \text { else. }\end{cases}
$$

Performing the same analysis for the holding company's deviating incentives under centralized decision making leads to the following lemma: ${ }^{13}$

Lemma 1 One-period deviation incentives imply that $p_{1, c}^{D}=p_{i, d}^{D}<p_{h, c}^{D}$.

Proof See the appendix.

If the holding company keeps pricing power and deviates, it will charge a higher price compared to the case where local units set prices and deviate. At first glance, this may not seem obvious as the collusive price by firm 1 is lower in the case without the delegation of the pricing decision, so one would expect the best reply to that price to be a lower price too. Whenever a firm deviates, however, it has to find an optimal balance between a reduction in price and an increase in market share. Therefore, a holding company charges a higher deviation price as a price cut applies to a greater market share. ${ }^{14}$

Given the results from the analysis so far, it is now possible to calculate the critical discount factors in order to compare the sustainability and profitability of collusive agreements under different decision-making rules.

\section{Sustainability of maximum prices under collusion}

In order to analyze the overall incentives to deviate from the maximum collusive prices, we calculate the respective critical discount factors. They define the range for which the maximum collusive prices can be sustained: The higher the discount factor, the smaller this range. First, we analyze how the internal decision-making process affects the deviation incentives for the holding company and its two local units. Let $\bar{\delta}_{h, c}:=\left(\pi_{h, c}^{D}-\pi_{h, c}^{C}\right) /\left(\pi_{h, c}^{D}-\pi_{h, c}^{N}\right)$ and $\bar{\delta}_{i, d}:=\left(\pi_{i, d}^{D}-\pi_{i, d}^{C}\right) /\left(\pi_{i, d}^{D}-\pi_{i, d}^{N}\right)$. We obtain:

Lemma 2 On the holding-company level, $\bar{\delta}_{h, c}<\bar{\delta}_{i, d}$ holds.

Proof See the appendix.

\footnotetext{
${ }^{13}$ Note that the holding company wants to serve the whole market for any $\tau \leq \check{\tau}$ where $\check{\tau} \approx 2.01244$.

${ }^{14}$ Moreover, if the holding company seeks to cover the whole market, the customer that is furthest away from each of the local units is located at a distance of only $1 / 3$.
} 
On the holding-company level, collusion is more stable under a centralized decisionmaking structure. Giving away the pricing decision to the local units will make deviation from the collusive agreement more likely when considering maximum collusive prices. The reason for this outcome is similar to the classic argument of why collusion becomes less stable if there are more parties to it. ${ }^{15}$ Deviating is much more attractive for a local unit as it also steals customers from the other local unit and not just from firm 1 . In addition, firm 1 charges a higher price for the case where pricing power is with the local units which makes deviation even more profitable. So although future punishment is harder, i.e. the competitive profits in future periods are lower if pricing rests with the local units, the first two effects outweigh the latter to give the result of Lemma 2 .

Next, we look at the outside firm and the holding company. Let $\bar{\delta}_{1, c}:=\left(\pi_{1, c}^{D}-\right.$ $\left.\pi_{1, c}^{C}\right) /\left(\pi_{1, c}^{D}-\pi_{1, c}^{N}\right)$. Then, we can state the following result:

Lemma 3 For the case where the holding company sets prices, it holds that $\bar{\delta}_{1, c}>$ $\bar{\delta}_{h, c}$.

Proof See the appendix.

The outside firm is more likely to deviate whenever the holding company does not delegate the pricing decision. Note that the holding company charges the higher collusive price. Hence, deviating is quite attractive for the outside firm as it is able to capture a large share of the market (or all of it, for that matter).

From a market point of view, we have to find the weakest link for the collusion with maximum prices, i.e. the firm with the largest critical discount factor, to determine whether collusion is possible or not. Lemma 3 and the fact that the deviation incentives are the same for all firms under decentralization imply that it is indeed the outside firm's behavior which is crucial for the stability of a collusive agreement from the perspective of the market as a whole. This is stated in the next proposition:

Proposition 2 There exists a $\tilde{\tau}<\bar{\tau}$ such that $\bar{\delta}_{1, c} \lesseqgtr \bar{\delta}_{1, d} \Leftrightarrow \tau \lesseqgtr \tilde{\tau}$, i.e. for low (high) transportation costs, the critical discount factor for the outside firm in a market with centralized decision making is smaller (greater) than under decentralization.

Proof See the appendix.

Proposition 2 shows that maximum collusive prices can be sustained for a broader range of discount factors if the holding company gives away (does not give away) the pricing decision and if the transportation costs are high (low). ${ }^{16}$ The intuition behind the above result is as follows: Both under centralized and decentralized decision making, the outside firm has the same deviation incentives, so it is sufficient to focus on its competitive and collusive profits. With respect to these profits, there are two effects which work in opposite directions: On the one hand, due to the bargaining process under centralization, the outside firm generates a higher

\footnotetext{
${ }^{15}$ See, e.g., Majerus (1988).

${ }^{16}$ Note that $\tilde{\tau} \approx 3.04168$.
} 
Table 1: Comparison of the critical discount factors

\begin{tabular}{cc}
\hline$\tau<\tilde{\tau}$ & $\tau>\tilde{\tau}$ \\
\hline$\delta_{h, c}<\delta_{1, c}<\delta_{i, d}$ & $\delta_{h, c}<\delta_{i, d}<\delta_{1, c}$ \\
\hline
\end{tabular}

collusive profit which stabilizes collusion. On the other hand, however, it faces a less severe punishment. For low values of the transportation costs, the latter effect is negligible as competitive profits for the outside firm are rather low both under centralization as well as decentralization. At the same time, the difference between the outside firm's collusive profit under both regimes is rather large (see remarks on Proposition 1). ${ }^{17}$ As a result, the outside firm is more likely to deviate under delegation, thus destabilizing collusion under a decentralized decision-making regime to a larger extent. The strength of these effects is reversed if transportation costs are high as the difference with respect to the competitive profits increases with the transportation costs. As a consequence, the centralization of decision-making powers leads to a destabilization of the collusive agreement. This is not necessarily what one expects as usually a lower number of firms in the market means that collusion can be sustained more easily. Here, however, the less severe punishment under centralized decision making turns this result around.

Table 1 compares all three critical discount factors for different values of the transportation cost parameter.

Next, we turn to the case where the industry's discount factor is below the critical discount factor and analyze the implications for the collusive prices.

\section{Collusion for discount factors below the critical ones}

As shown in Chang (1991), a lower discount factor than the critical one does not necessarily mean that collusion is not sustainable in a situation where firms are horizontally differentiated. Firms may not be able to charge their maximum collusive prices but prices higher than the competitive prices can still be supported as a collusive outcome as long as the discount factor is strictly positive. In order to understand the basic mechanism, consider the case of decentralized decision-making powers. Now take the case where $\tau>\hat{\tau}$, i.e. a deviating firm does not want to capture the whole market. Clearly, if the collusive price has to be adjusted downwards, the incentive to seize all of the market is further reduced. Therefore, collusion will be stable as long as

$$
\frac{p_{i, d}^{C}}{3(1-\delta)} \geq \frac{\left(9 p_{i, d}^{C}+\tau\right)^{2}}{108 \tau}+\frac{\delta \pi_{i, d}^{N}}{1-\delta} \Leftrightarrow p_{i, d}^{C}(\delta) \leq \frac{\tau(1+3 \delta)}{9(1-\delta)}
$$

holds. $^{18}$

Hence, one arrives at a $\delta$-adjusted collusive price which is strictly increasing in the

\footnotetext{
${ }^{17}$ E.g., for $\tau \rightarrow 0$, we get $\pi_{1, c}^{N} \rightarrow 0$ and $\pi_{i, d}^{N} \rightarrow 0$ whereas collusive profits are strictly positive and $\pi_{1, c}^{C}>\pi_{i, d}^{C}$.

${ }^{18}$ See the proof of Proposition 3 in the appendix for an analysis of the case where $\tau \leq \hat{\tau}$.
} 
discount factor. If the discount factor converges to 0 , then the price converges to the competitive price. We will not derive the explicit collusive prices for the scenario with centralized price setting as computations are not tractable.

From the competitive case, we know that centralizing the price-setting decision is more profitable, i.e. $\pi_{h, c}^{N}>\pi_{h, d}^{N}$. Proposition 1 states that when comparing maximum collusive profits, delegating price-setting power is more profitable for the holding company, i.e. $\pi_{h, c}^{C}<\pi_{h, d}^{C}$. Combining these results with the general insights from the approach by Chang (1991), we can state the following proposition:

Proposition 3 For any $\tau \in(0, \bar{\tau}]$, there exist $\delta^{*}$ and $\delta^{* *}$ with $0<\delta^{*} \leq \delta^{* *} \leq \bar{\delta}_{i, d}$ such that if $\delta \leq \delta^{*} \Rightarrow \pi_{h, c}^{C} \geq \pi_{h, d}^{C}$ and if $\delta \geq \delta^{* *} \Rightarrow \pi_{h, c}^{C} \leq \pi_{h, d}^{C}$.

Proof See the appendix.

Hence, the profitability of collusion depends on the centralization of the price-setting decision. Whereas centralization makes sense for lower discount factors, high discount factors suggest the decentralization of internal decision responsibilities. For two values of the transportation costs ( $\tau$ relatively small and $\tau$ large), we derived the respective collusive profits under centralization numerically to compare both regimes. The results are given in Figures 1 and 2.

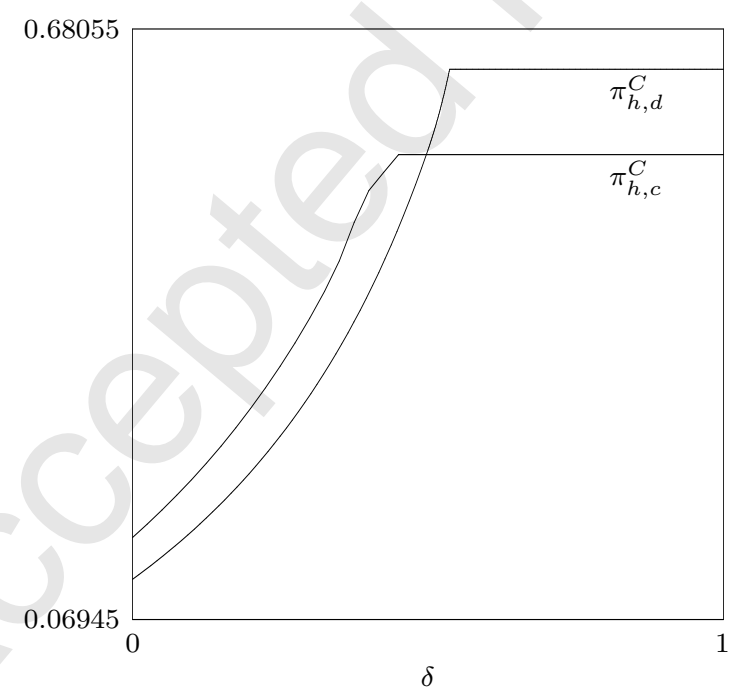

Figure 1: Comparison of collusive profits under both regimes (for $\tau=3 / 2$ ) 


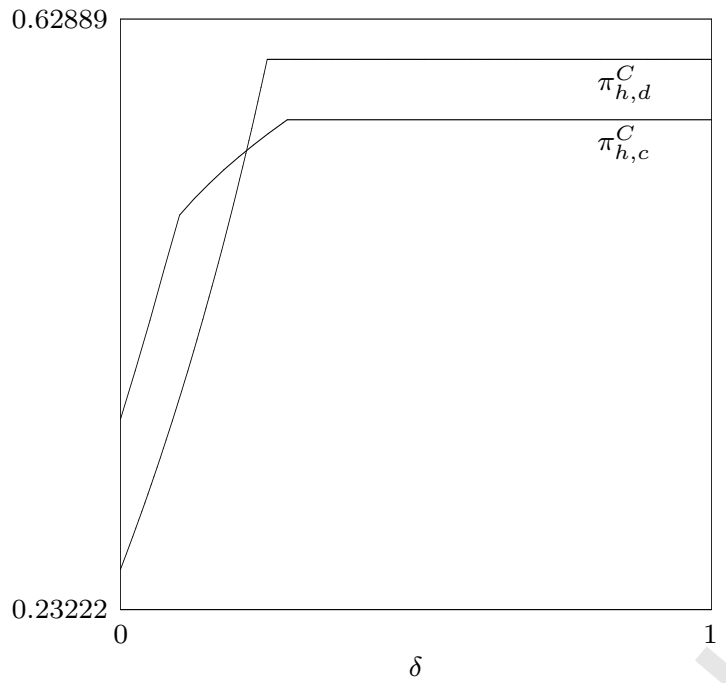

Figure 2: Comparison of collusive profits under both regimes (for $\tau=\bar{\tau}=7 / 2$ )

\section{Conclusions}

In this article, we analyze how different internal decision-making structures affect the stability of collusive agreements. Our findings can be summarized as follows. Making use of a three-firm spatial model à la Salop (1979), we find that on the holding-company level, (a) the maximum profit from collusion is higher if the holding company delegates the pricing decision and (b) if it does so, the incentives for its local units to deviate from the collusive agreement are increased. From the perspective of the market as a whole, however, we find that (c) the critical discount factor is determined by the outside firm: It is higher (lower) in the centralized decisionmaking regime if transportation costs are high (low).

Summing up, antitrust and competition authorities trying to prevent coordinated effects should be careful when imposing certain restrictions with respect to the decision-making structure on merging firms. While the "maintenance of the acquired firm as a separate and distinct corporate entity with a separate board of directors" (see the introduction) might restrain the merged firm in some of its detrimental economic behavior, it might, however, enable the market as a whole to collude.

\section{References}

Abreu, D., 1986. Extremal equilibria of oligopolistic supergames. Journal of Economic Theory 39, 191-225.

Abreu, D., 1988. On the theory of infinitely repeated games with discounting. Econometrica 56, 383-396.

Abreu, D., Pearce, D.G., Stacchetti, E., 1986. Optimal cartel equilibria with imperfect monitoring. Journal of Economic Theory 39, 251-269. 
Baye, M.R., Crocker, K.J., Ju, J., 1996. Divisionalization, franchising and divestiture incentives in oligopoly. The American Economic Review 86, 223-236.

Campbell, A.N., Halladay, C.W., 2002. The use of behavioural remedies in Canadian merger law. Mimeo. McMillan Binch LLP.

Chang, M.-H., 1991. The effects of product differentiation on collusive pricing. International Journal of Industrial Organization 9, 453-469.

Creane, A., Davidson, C., 2004. Multidivisional firms, internal competition, and the merger paradox. Canadian Journal of Economics 37, 951-977.

Friedman, J., 1971. A non-cooperative equilibrium for supergames. The Review of Economic Studies 38, 1-12.

Häckner, J., 1996. Optimal symmetric punishments in a Bertrand differentiated products duopoly. International Journal of Industrial Organization 14, 611-630.

Harrington, J.E., 1991. The determination of price and output quotas in a heterogeneous cartel. International Economic Review 32, 767-792.

Harrington, J.E., Hobbs, B.F., Pang, J.S., Liu, A., Roch, G., 2005. Collusive game solutions via optimization. Mathematical Programming, Series B 104, 407-435.

Hotelling, H., 1929. Stability in competition. The Economic Journal 39, 41-57.

Huck, S., Konrad, K.A., Müller, W., 2004. Profitable horizontal mergers without cost advantages: The role of internal organization, information and market structure. Economica 71, 575-587.

Lambertini, L., Trombetta, M., 2002. Delegation and firms' ability to collude. Journal of Economic Behavior \& Organization 47, 359-373.

Levy, D.T., Reitzes, J.D., 1992. Anticompetitive effects of mergers in markets with localized competition. Journal of Law, Economics, \& Organization 8, 427-440.

Majerus, D.W., 1988. Price vs. quantity competition in oligopoly supergames. Economics Letters 27, 293-297.

Muthoo, A., 1999. Bargaining Theory with Applications. Cambridge: Cambridge University Press.

Nash, J.F., 1950. The bargaining problem. Econometrica 18, 155-162.

Olaizola, N., 2007. Cartel formation and managerial incentives. Spanish Economic Review 9, 219-236.

Osborne, M.J., Rubinstein, A., 1990. Bargaining and Markets. San Diego: Academic Press.

Posada, P., Straume, O.R., 2004. Merger, partial collusion and relocation. Journal of Economics 83, 243-265. 
Prechel, H., Boies, J., Woods, T., 1999. Debt, mergers and acquisitions, institutional arrangements and change to the multilayered subsidiary form. Social Sciences Quarterly 80, 115-135.

Salop, S.C., 1979. Monopolistic competition with outside goods. The Bell Journal of Economics 10, 141-156.

Shelanski, H.A., Sidak, J.G., 2001. Antitrust divestiture in network industries. The University of Chicago Law Review 68, 1-99.

Spagnolo, G., 2005. Managerial incentives and collusive behavior. European Economic Review 49, 1501-1523.

Sundaram, R.K., 1996. A First Course in Optimization Theory. Cambridge: Cambridge University Press.

Timmins, P.V., 1986. Divestiture as a remedy in private actions brought under Section 16 of the Clayton Act. Michigan Law Review 84, 1579-1597.

\section{Appendix}

\section{Derivation of maximum collusive prices under centralization}

Proof We divide the proof into two parts where we (a) derive the maximum collusive prices assuming full market coverage and (b) show that partial market coverage cannot be optimal.

Ad (a): As explained above, the maximization problem concerning collusive prices under full market coverage amounts to $\max _{p_{1, c}^{C}, p_{h, c}^{C}} \Pi_{c}^{C}:=\left(\pi_{1, c}^{C}-\pi_{1, c}^{N}\right)\left(\pi_{h, c}^{C}-\pi_{h, c}^{N}\right)$. Note first that if both collusive prices are below $1-\tau / 36$, then increasing these prices simultaneously by the same amount such that the market shares are not changed leads to an increase in the product. There are two cases: The price charged by the outside firm may either be (i) higher or (ii) smaller than the one charged by the holding company.

Ad (i): As argued above, this case implies that $p_{1, c}^{C} \geq 1-\tau / 36$ must hold. At the same time, $p_{h, c}^{C}<1-\tau / 36$ must be true in order for the market to be covered. However, $p_{h, c}^{C}$ cannot be too small as the outside firm needs to have an incentive to participate. More precisely, it must hold that $\pi_{1, c}^{C}-\pi_{1, c}^{N} \geq 0 \Leftrightarrow p_{h, c}^{C} \geq p_{1, c}^{C}+$ $16 \tau^{2} /\left(729 p_{1, c}^{C}\right)-\tau / 9$. Note that this expression attains a minimum when $p_{1, c}^{C}$ is equal to the competitive price $p_{1, c}^{N}$. This implies that $p_{h, c}^{C} \geq p_{h, c}^{N}$.

Next, we get

$$
\begin{aligned}
\frac{\partial \prod_{c}^{C}}{\partial p_{1, c}^{C}}=\frac{p_{1, c}^{C}\left(-19683 p_{1, c}^{C} p_{h, c}^{C}+26244 p_{h, c}^{C}{ }^{2}-1458 p_{h, c}^{C} \tau+450 \tau^{2}\right)}{729 \tau^{2}} & \\
& -\frac{9 p_{h, c}^{C}{ }^{3}}{\tau^{2}}+\frac{p_{h, c}^{C}{ }^{2}}{\tau}-\frac{23 p_{h, c}^{C}}{81}-\frac{25 \tau}{729} .
\end{aligned}
$$


Solving $\partial \Pi_{c}^{C} / \partial p_{1, c}^{C}=0$ for $p_{1, c}^{C}$ gives the following two solutions:

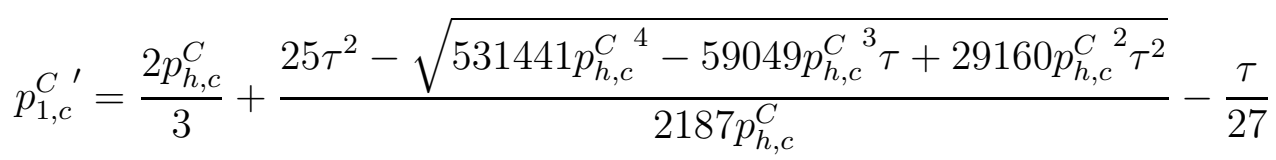

as well as

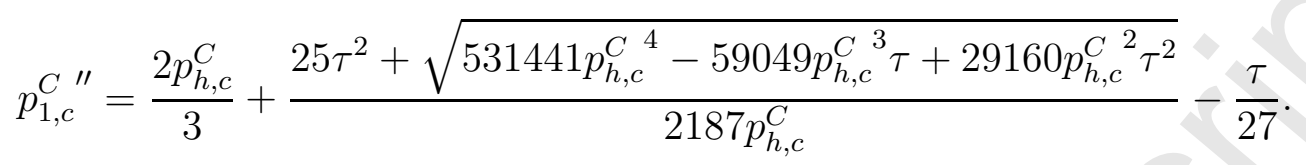

From the second-order condition given by

$$
\frac{\partial^{2} \Pi_{c}^{C}}{\partial p_{1, c}^{C}}=-\frac{2\left(2187 p_{1, c}^{C} p_{h, c}^{C}-1458 p_{h, c}^{C}{ }^{2}+81 p_{h, c}^{C} \tau-25 \tau^{2}\right)}{81 \tau^{2}}
$$

we observe that

$$
\begin{aligned}
& \left.\frac{\partial^{2} \Pi_{c}^{C}}{\partial p_{1, c}^{C}{ }^{2}}\right|_{p_{1, c}^{C}=p_{1, c}^{C}{ }^{\prime}} \\
& =\frac{2 \sqrt{531441 p_{h, c}^{C}{ }^{4}-59049 p_{h, c}^{C}{ }^{3} \tau+29160 p_{h, c}^{C}{ }^{2} \tau^{2}-10125 p_{h, c}^{C} \tau^{3}+625 \tau^{4}}}{81 \tau^{2}}>0 .
\end{aligned}
$$

In a similar way, one can show that the second-order condition is strictly smaller than 0 for $p_{1, c}^{C}{ }^{\prime \prime}$. For $p_{1, c}^{C}$ "' to be part of the equilibrium defined above, it must hold that $p_{1, c}^{C}{ }^{\prime \prime} \geq 1-\tau / 36$. However, for any $p_{h, c}^{C} \in\left[p_{h, c}^{N}, 1-\tau / 36\right) \Rightarrow p_{1, c}^{C}{ }^{\prime \prime}<1-\tau / 36$. Thus, $p_{1, c}^{C}>p_{h, c}^{C}$ cannot be the solution.

Ad (ii): From (i) and the argument put forward above, we know that $p_{1, c}^{C}<p_{h, c}^{C}=$ $1-\tau / 36$ must hold. Now let $A:=136048896-30233088+9354528 \tau^{2}-3053376 \tau^{3}+$ $238165 \tau^{4}{ }^{19}$ Then, plugging $p_{h, c}^{C}=1-\tau / 36$ into $p_{1, c}^{C}$ " gives the optimal price for the outside firm:

$$
p_{1, c}^{C}=\frac{23328-2592 \tau+454 \tau^{2}+\sqrt{A}}{972(36-\tau)} .
$$

Thus, profits are given by

$$
\pi_{1, c}^{C}=\frac{\left(23328-2592 \tau+454 \tau^{2}+\sqrt{A}\right)\left(11664+4536 \tau-535 \tau^{2}-\sqrt{A}\right)}{314928 \tau(36-\tau)^{2}}
$$

and

$$
\pi_{h, c}^{C}=\pi_{2, c}^{C}+\pi_{3, c}^{C}=\frac{-11664+7128 \tau+211 \tau^{2}+\sqrt{A}}{11664 \tau} .
$$

Ad (b): When it comes to partial market coverage, there are three cases which are relevant: (i) no full coverage between any two firms, (ii) no coverage between the outside firm and the local units, and (iii) no coverage between the local units.

\footnotetext{
${ }^{19}$ Note that $A \geq 0 \forall \tau \in(0, \bar{\tau}]$.
} 
Ad (i): Note first that in this case, we must have $p_{h, c}^{C}>1-\tau / 36$ so that the market between the two local units is not covered. If the market is not covered between any two of the three firms, the maximization problem boils down to

$$
\max _{p_{1, c}^{C}, p_{h, c}^{C}} \Pi_{c}^{C^{\prime}}:=\left(2 p_{1, c}^{C} \sqrt{\frac{1-p_{1, c}^{C}}{\tau}}-\pi_{1, c}^{N}\right)\left(4 p_{h, c}^{C} \sqrt{\frac{1-p_{h, c}^{C}}{\tau}}-\pi_{h, c}^{N}\right) .
$$

Hence, one gets

$$
\frac{\partial \Pi_{c}^{C^{\prime}}}{\partial p_{h, c}^{C}}=\left(2 p_{1, c}^{C} \sqrt{\frac{1-p_{1, c}^{C}}{\tau}}-\pi_{1, c}^{N}\right)\left(-\frac{3 p_{h, c}^{C}-2}{\sqrt{\tau\left(1-p_{h, c}^{C}\right)}}\right) .
$$

Note that $\partial \Pi_{c}^{C^{\prime}} / \partial p_{h, c}^{C}>0$ only holds if $p_{h, c}^{C}<2 / 3$ which contradicts the condition that $p_{h, c}^{C}>1-\tau / 36$ must hold.

Ad (ii): This case requires $p_{h, c}^{C} \leq 1-\tau / 36$ to hold which implies that $p_{1, c}^{C}>1-\tau / 36$ must be true in order to make sure that the market between the outside firm and one of the two local units will indeed not be covered. The maximization problem can be written as

$$
\max _{p_{1, c}^{C}, p_{h, c}^{C}} \Pi_{c}^{C^{\prime \prime}}:=\left(\frac{2 p_{1, c}^{C}\left(1-p_{1, c}^{C}\right)}{\tau}-\pi_{1, c}^{N}\right)\left(2 p_{h, c}^{C}\left(\frac{1}{6}+\sqrt{\frac{1-p_{h, c}^{C}}{\tau}}\right)-\pi_{h, c}^{N}\right) .
$$

Thus, we get

$$
\frac{\partial \Pi_{c}^{C^{\prime \prime}}}{\partial p_{1, c}^{C}}=\left(-\frac{3 p_{1, c}^{C}-2}{\sqrt{\tau\left(1-p_{1, c}^{C}\right)}}\right)\left(2 p_{h, c}^{C}\left(\frac{1}{6}+\sqrt{\frac{1-p_{h, c}^{C}}{\tau}}\right)-\pi_{h, c}^{N}\right) .
$$

Again, $\partial \Pi_{c}^{C^{\prime \prime}} / \partial p_{1, c}^{C}>0$ is only true if $p_{1, c}^{C}<2 / 3$ which is not compatible with the condition that $p_{1, c}^{C}>1-\tau / 36$ must hold.

Ad (iii): Note that we must have $p_{h, c}^{C}>1-\tau / 36$ which implies that $p_{1, c}^{C}<1-\tau / 36$ must hold. We then face the following maximization problem:

$$
\begin{aligned}
\max _{p_{1, c}^{C}, p_{h, c}^{C}} \Pi_{c}^{C^{\prime \prime \prime}}:=\left(2 p_{1, c}^{C}\right. & \left.\left(\frac{1}{6}-\frac{3\left(p_{1, c}^{C}-p_{h, c}^{C}\right)}{2 \tau}\right)-\pi_{1, c}^{N}\right) \\
& \times\left(2 p_{h, c}^{C}\left(\sqrt{\frac{1-p_{h, c}^{C}}{\tau}}+\frac{1}{6}+\frac{3\left(p_{1, c}^{C}-p_{h, c}^{C}\right)}{2 \tau}\right)-\pi_{h, c}^{N}\right) .
\end{aligned}
$$

We start by differentiating with respect to $p_{1, c}^{C}$ and find that both $\partial \Pi_{c}^{C^{\prime \prime \prime}} / \partial p_{1, c}^{C}=0$ and $\partial^{2} \Pi_{c}^{C^{\prime \prime \prime}} / \partial p_{1, c}^{C}{ }^{2}<0$ hold for some solution denoted $p_{1, c}^{C}{ }^{*}$. Next, we check whether an improvement is possible for any $p_{h, c}^{C}>1-\tau / 36$. To this end, solve $\left.\Pi_{c}^{C^{\prime \prime \prime}}\right|_{p_{1, c}^{C}=p_{1, c}^{C} *}>$ $\left.\Pi_{c}^{C}\right|_{p_{1, c}^{C}=\frac{23328-2592 \tau+454 \tau^{2}+\sqrt{A}}{972(36-\tau)}, p_{h, c}^{C}=1-\frac{\tau}{36}}$ for $p_{h, c}^{C}$. We find that for any $\tau \leq \bar{\tau}$, there is no 
solution to the problem which satisfies $p_{h, c}^{C}>1-\tau / 36$.

\section{Proof of Lemma 1}

Proof Note first that for $\tau=\bar{\tau}$, it is true that $p_{1, c}^{D}<p_{h, c}^{D}$. Next, consider $\tau<\bar{\tau}$ : We look for a solution to $p_{1, c}^{D}=p_{h, c}^{D}$ with respect to $\tau$ in the three relevant regions defined by the deviation prices, i.e. (a) $\tau \in(0, \hat{\tau}]$, (b) $\tau \in(\hat{\tau}, \check{\tau}]$, and (c) $\tau \in(\check{\tau}, \bar{\tau}]$. In all three cases (a)-(c), solving $p_{1, c}^{D}=p_{h, c}^{D}$ for $\tau$ does not give a (real-number) solution at all. As the deviation prices are continuous, we can conclude that $p_{1, c}^{D}<p_{h, c}^{D}$ must hold for any $\tau \in(0, \bar{\tau}]$.

\section{Proof of Lemma 2}

Proof For $\tau=\bar{\tau}$, it holds that $\bar{\delta}_{h, c}<\bar{\delta}_{i, d}$. Now consider $\tau<\bar{\tau}$ : We check whether a solution to $\bar{\delta}_{h, c}=\bar{\delta}_{i, d}$ with respect to $\tau$ exists in the three relevant regions defined by the deviation prices (see proof of Lemma 1). In case (a), we find that $\bar{\delta}_{h, c}=\bar{\delta}_{i, d}$ only holds if $\tau \approx 2.76923$ or $\tau \approx 4.43725$ which contradicts the condition that $\tau \in(0, \hat{\tau}]$. Proceeding with case (b), one gets $\bar{\delta}_{h, c}=\bar{\delta}_{i, d} \Leftrightarrow \tau \approx 9.66200$ which conflicts with the condition that $\tau \in(\hat{\tau}, \check{\tau}]$. Finally, in case (c), we find that $\bar{\delta}_{h, c}=\bar{\delta}_{i, d}$ is true only if $\tau \approx-5.08691$ which contradicts the condition that $\tau \in(\check{\tau}, \bar{\tau}]$. As the discount factors are continuous, we know that $\bar{\delta}_{h, c}<\bar{\delta}_{i, d}$ must hold for any $\tau \in(0, \bar{\tau}]$.

\section{Proof of Lemma 3}

Proof We find that if $\tau=\bar{\tau}$, then $\bar{\delta}_{1, c}>\bar{\delta}_{h, c}$. Turning to $\tau<\bar{\tau}$, we need to look for a solution to $\bar{\delta}_{1, c}=\bar{\delta}_{h, c}$ with respect to $\tau$ in the three relevant regions (see proof of Lemma 1). For case (a), one gets $\bar{\delta}_{1, c}=\bar{\delta}_{h, c}$ for $\tau \approx 2.54409$ which conflicts with the condition that $\tau \in(0, \hat{\tau}]$. In case (b), we find that $\bar{\delta}_{1, c}=\bar{\delta}_{h, c}$ is true only if $\tau \approx-7.75837$ or $\tau \approx 9.84511$ which contradicts the condition that $\tau \in(\hat{\tau}, \tilde{\tau}]$. Finally, in case (c), solving $\bar{\delta}_{1, c}=\bar{\delta}_{h, c}$ for $\tau$ does not give any solution. Since the discount factors are continuous, we can conclude that $\bar{\delta}_{1, c}>\bar{\delta}_{h, c}$ must hold for any $\tau \in(0, \bar{\tau}]$.

\section{Proof of Proposition 2}

Proof For $\tau=\bar{\tau}, \bar{\delta}_{1, c}>\bar{\delta}_{i, d}$ is true. Proceeding with the analysis of the situation where $\tau<\bar{\tau}$, we look for a solution to $\bar{\delta}_{1, c}=\bar{\delta}_{i, d}$ with respect to $\tau$ in the two relevant regions defined by the deviation prices, i.e. (a) $\tau \in(0, \hat{\tau}]$ and (b) $\tau \in(\hat{\tau}, \bar{\tau}]$. In case $(\mathrm{a})$, we find that $\bar{\delta}_{1, c}=\bar{\delta}_{i, d}$ only holds if $\tau \approx-24.77747$ which contradicts the condition that $\tau \in(0, \hat{\tau}]$. Turning to case (b), we find that $\bar{\delta}_{1, c}=\bar{\delta}_{i, d}$ is true for $\tau \approx 3.04168$. As the discount factors are continuous, the proposition follows.

\section{Proof of Proposition 3}

Proof The proof is divided into two parts: We (a) complete the analysis for the situation with decentralization and (b) analyze the centralization case. 
Ad (a): Consider the decentralization case where $\tau \leq \hat{\tau}$. If the collusive price has to be adjusted downwards, a deviating firm may no longer try to seize all of the market. If it still does, it will set a deviation price of $1 / 6-3\left(p_{i, d}^{D}-p_{i, d}^{C}\right) / 2 \tau=1 / 2 \Leftrightarrow$ $p_{i, d}^{D}=p_{i, d}^{C}-2 \tau / 9$. Given this deviation price, the following condition must hold for collusion to be sustainable: $p_{i, d}^{C} / 3(1-\delta) \geq p_{i, d}^{C}-2 \tau / 9+\delta \pi_{i, d}^{N} /(1-\delta) \Leftrightarrow p_{i, d}^{C}(\delta) \leq$ $\tau(6-7 \delta) / 9(2-3 \delta)$.

Next, we need to check whether serving the whole market is optimal for any value of $\delta$. For a given $p_{i, d}^{C}$, covering the whole market is indeed (weakly) optimal as long as $p_{i, d}^{C}-2 \tau / 9 \geq\left(9 p_{i, d}^{C}+\tau\right)^{2} / 108 \tau \Leftrightarrow p_{i, d}^{C} \geq 5 \tau / 9$. Thus, setting $p_{i, d}^{C}=\tau(6-7 \delta) / 9(2-3 \delta)$ and solving the inequality for $\delta$ reveals that $\tau(6-7 \delta) / 9(2-3 \delta) \geq 5 \tau / 9 \Leftrightarrow \delta \geq 1 / 2$.

Hence, we can characterize the adjusted collusive prices under decentralization for any $\delta \leq \bar{\delta}_{i, d}$ as follows: ${ }^{20}$

$$
p_{i, d}^{C}(\delta)= \begin{cases}\frac{\tau(6-7 \delta)}{9(2-3 \delta)} & \text { if } \tau \leq \hat{\tau} \wedge \delta \geq \frac{1}{2} \\ \frac{\tau(1+3 \delta)}{9(1-\delta)} & \text { else. }\end{cases}
$$

Ad (b): We prove that a solution to the maximization problem exists. ${ }^{21}$ The maximization problem under centralization is given by

$$
\max _{p_{1, c}^{C}, p_{h, c}^{C}} \Pi_{c}^{C}
$$

subject to

$$
\frac{2 p_{1, c}^{C}\left(\frac{1}{6}-\frac{3\left(p_{1, c}^{C}-p_{h, c}^{C}\right)}{2 \tau}\right)}{1-\delta} \geq p_{h, c}^{C}-\frac{2 \tau}{9}+\frac{\delta \pi_{1, c}^{N}}{1-\delta}
$$

and

$$
\frac{2 p_{h, c}^{C}\left(\frac{1}{3}-\frac{3\left(p_{h, c}^{C}-p_{1, c}^{C}\right)}{2 \tau}\right)}{1-\delta} \geq p_{1, c}^{C}-\frac{\tau}{9}+\frac{\delta \pi_{h, c}^{N}}{1-\delta}
$$

if a deviating firm covers the whole market. ${ }^{22}$ If it does not, the respective incentive constraints change to

$$
\frac{2 p_{1, c}^{C}\left(\frac{1}{6}-\frac{3\left(p_{1, c}^{C}-p_{h, c}^{C}\right)}{2 \tau}\right)}{1-\delta} \geq \frac{\left(9 p_{h, c}^{C}+\tau\right)^{2}}{108 \tau}+\frac{\delta \pi_{1, c}^{N}}{1-\delta}
$$

and

$$
\frac{2 p_{h, c}^{C}\left(\frac{1}{3}-\frac{3\left(p_{h, c}^{C}-p_{1, c}^{C}\right)}{2 \tau}\right)}{1-\delta} \geq \frac{\left(9 p_{1, c}^{C}+2 \tau\right)^{2}}{108 \tau}+\frac{\delta \pi_{h, c}^{N}}{1-\delta} .
$$

According to the Weierstrass Theorem, a solution to the maximization problem

\footnotetext{
${ }^{20}$ Note that $\bar{\delta}_{i, d} \lesseqgtr 1 / 2 \Leftrightarrow \tau \gtreqless \hat{\tau}$.

${ }^{21}$ Due to the complexities of the non-linear optimization problem in the case of centralized price setting, we cannot derive the explicit expressions for the adjusted collusive prices.

${ }^{22}$ As the numerical simulations suggest and in line with the insights from the decentralization case, this is true for relatively low values of $\tau$ and higher values of $\delta$.
} 
exists if (i) $\Pi_{c}^{C}$ is continuous on its domain and (ii) if the (non-empty) set of inequality constraints is compact (i.e. closed and bounded). ${ }^{23}$ Clearly, (i) is satisfied. To check condition (ii), we need to verify that the relevant inequalities can be satisfied at the same time. This, however, is always the case as any incentive constraint is satisfied if $p_{1, c}^{C}=p_{1, c}^{N}$ and $p_{h, c}^{C}=p_{h, c}^{N}$. Hence, the lowest collusive profit is equal to the competitive profit.

As $\pi_{i, d}^{C}(\delta) \leq \pi_{h, c}^{N} \Leftrightarrow \delta \leq 7 / 79, \delta^{*}$ exists. Moreover, we know from Proposition 1 that $\pi_{h, c}^{C}<\pi_{h, d}^{C}$ if $\delta$ is large. Hence, $\delta^{* *}$ exists.

$\overline{{ }^{23} \text { See, e.g., Sundaram (1996), chapter } 3}$. 